\title{
Article \\ Cappable-Seq Reveals Specific Patterns of Metabolism and Virulence for Salmonella Typhimurium Intracellular Survival within Acanthamoeba castellanii
}

\author{
Alexander S. Balkin 1,*, Andrey O. Plotnikov 2(D, Natalia E. Gogoleva ${ }^{2}$, Yuri V. Gogolev ${ }^{2,3}$, \\ Kirill N. Demchenko ${ }^{4}$ (D) and Sergey V. Cherkasov ${ }^{1}$ \\ 1 Laboratory of Biomedical Technologies, Institute for Cellular and Intracellular Symbiosis, Ural Branch of \\ Russian Academy of Sciences, 460000 Orenburg, Russia; cherkasovsv@yandex.ru \\ 2 "Persistence of Microorganisms" Science Resource Center, Institute for Cellular and Intracellular Symbiosis, \\ Ural Branch of Russian Academy of Sciences, 460000 Orenburg, Russia; protoz@mail.ru (A.O.P.); \\ negogoleva@gmail.com (N.E.G.); gogolev@kibb.knc.ru (Y.V.G.) \\ 3 Federal Research Center Kazan Scientific Center of the Russian Academy of Sciences, Kazan Institute of \\ Biochemistry and Biophysics, 420111 Kazan, Russia \\ 4 Laboratory of Cellular and Molecular Mechanisms of Plant Development, Komarov Botanical Institute, \\ Russian Academy of Sciences, 197376 Saint Petersburg, Russia; Demchenko@binran.ru \\ * Correspondence: balkinas@yandex.ru
}

check for updates

Citation: Balkin, A.S.; Plotnikov, A.O.; Gogoleva, N.E.; Gogolev, Y.V.; Demchenko, K.N.; Cherkasov, S.V. Cappable-Seq Reveals Specific Patterns of Metabolism and Virulence for Salmonella Typhimurium Intracellular Survival within Acanthamoeba castellanii. Int. J. Mol. Sci. 2021, 22, 9077. https://doi.org/ $10.3390 /$ ijms 22169077

Academic Editor: Rustam I. Aminov

Received: 28 April 2021

Accepted: 19 August 2021

Published: 23 August 2021

Publisher's Note: MDPI stays neutral with regard to jurisdictional claims in published maps and institutional affiliations.

Copyright: (c) 2021 by the authors. Licensee MDPI, Basel, Switzerland. This article is an open access article distributed under the terms and conditions of the Creative Commons Attribution (CC BY) license (https:/ / creativecommons.org/licenses/by/ $4.0 /)$.

\begin{abstract}
The bacterial pathogen Salmonella enterica, which causes enteritis, has a broad host range and extensive environmental longevity. In water and soil, Salmonella interacts with protozoa and multiplies inside their phagosomes. Although this relationship resembles that between Salmonella and mammalian phagocytes, the interaction mechanisms and bacterial genes involved are unclear. Here, we characterized global gene expression patterns of $S$. enterica serovar Typhimurium within Acanthamoeba castellanii at the early stage of infection by Cappable-Seq. Gene expression features of $S$. Typhimurium within A castellanii were presented with downregulation of glycolysis-related, and upregulation of glyoxylate cycle-related genes. Expression of Salmonella Pathogenicity Island-1 (SPI-1), chemotaxis system, and flagellar apparatus genes was upregulated. Furthermore, expression of genes mediating oxidative stress response and iron uptake was upregulated within $A$. castellanii as well as within mammalian phagocytes. Hence, global $S$. Typhimurium gene expression patterns within A. castellanii help better understand the molecular mechanisms of Salmonella adaptation to an amoeba cell and intracellular persistence in protozoa inhabiting water and soil ecosystems.
\end{abstract}

Keywords: Acanthamoeba; Salmonella; protozoa; Cappable-Seq; glyoxylate cycle; oxidative stress; SPI; persistence

\section{Introduction}

Salmonellosis is the second-most common human zoonosis after Campylobacter infection, despite a significant decrease in the number of confirmed cases in the EU/EEA since 2008 [1]. In 2017, there were 91,662 confirmed cases of salmonellosis in Europe [1].

In natural reservoirs, Salmonella strains may share their habitat with phagocytic protozoa [2,3] that use bacteria as food [4,5] and engulf them by phagocytosis [6,7]. However, Salmonella can survive [8-10] and replicate within protozoan phagosomes [11,12]. For this reason, certain protozoa are environmental reservoirs for bacterial pathogens. Multiplication of Salmonella in protozoan phagosomes increase bacterial virulence [13], enhance their resistance, and enable them to persist in mammalian phagocytes $[5,14]$. Therefore, the study of the interactions between Salmonella and protozoa is crucial for control human and animal salmonellosis.

Salmonella survival in mammalian phagocytes and nonphagocytic cells has been investigated with omics technologies [15-20]. Within mammalian phagocytes gene expression 
of the type III secretion system (T3SS), iron uptake and oxidative stress response is strongly upregulated. However, expression of bacterial flagellar and chemotaxis genes is downregulated inside mammalian phagocytes and nonphagocytic cells $[15,17,19,20]$.

The transcriptional profile of Salmonella within mammalian phagosomes is well described. Nevertheless, bacterial gene expression in protozoan Salmonella-containing vacuoles (SCV) remains unclear. qRT-PCR analyses have disclosed that the expression of Salmonella Pathogenicity Islands (SPI) genes was similar in both protozoan SCV and mammalian macrophages [21]. In Acanthamoeba polyphaga phagosomes, SPI-2 genes were upregulated [21] whereas SPI-1 genes were not. Only two studies were published on total gene expression in Salmonella engulfed by heterotrophic protists such as the ciliate Tetrahymena sp. and the amoeba Acanthamoeba rhysodes [14,22]. Microarray methods revealed that several genes required for Salmonella survival and replication in mammalian phagocytes were also upregulated in protozoa [14,22]. Analysis of the host-pathogen interactions between wildtype or mutant $S$. Typhimurium and the social amoeba Dictyostelium discoideum showed that aromatic compounds, lipopolysaccharides (LPSs), O-antigen, SPI-1, SPI-2, SPI-6, and PhoP/PhoQ are required for Salmonella to survive within protozoa [12].

Despite the major ecological and epidemiological significance of Salmonella, its transcriptome and metabolism in protozoan phagosomes are poorly understood because of the limitations of the methods used and the high costs associated with them. Protozoa are rarely used as model organisms. Consequently, commercially available solutions for cDNA libraries provide inefficient removal of ribosomal and transport protist RNA. Nevertheless, new methods such as dRNA-Seq [23] and Cappable-Seq [24] generate RNA-Seq libraries with mRNA-enriched transcripts. To the best of our knowledge, Salmonella gene expression within protozoan phagosomes has not yet been investigated by next-generation sequencing (NGS).

The aim of our study was to reveal specific changes of metabolism and virulence for intracellular survival of $S$. Typhimurium within Acanthamoeba castellanii using CappableSeq. Additionally, we compared the transcriptional profile of Salmonella located within Acanthamoeba against those for Salmonella within macrophages, epithelial cells, and fibroblasts. Cappable-Seq provided new data for the global evaluation of the Salmonella primary transcriptome. We found that expression of genes mediating oxidative stress response and iron uptake was upregulated within $A$. castellanii as well as within mammalian phagocytes. Unlike infection models of macrophages and epithelial cells, Salmonella in Acanthamoeba SCV at the early stage of infection presented with specific features, such as downregulation of glycolysis-related genes and upregulation of glyoxylate cycle-related, SPI-1, chemotaxis system, and flagellar apparatus genes. Besides, expression of SPI-2 genes was unaltered, like recently shown in a fibroblast infection model [20]. These observations help explain the ability of Salmonella to survive inside protozoa and persist in the environment.

\section{Results}

\subsection{Sequencing}

A total of $>71$ million single-end reads were generated and represented six libraries under two culture conditions, namely Salmonella in Acanthamoeba SCV (SA) vs. Salmonella (S) in the absence of the protists (control). Over $99 \%$ reads of the control libraries were mapped to the S. enterica serovar Typhimurium 14028S genome (GCA_000022165.1). Most of the library reads for the SA cultures (75-92\%) were mapped to the $A$. castellanii genome (GCA_000313135.1). The proportion of reads mapped to the Salmonella genome was in the range of $8-15 \%$ (Table $\mathrm{S} 1$ ).

There were 571 operons (DEOs) that significantly differentially expressed (FDRcorrected $p=0.05$; minimum normalized read count $=10 ; \log _{2}$ fold change $>1$ ) in Salmonella within Acanthamoeba compared to control culture (Table S3). In the SA libraries, 289 operons were upregulated and 282 were downregulated. From 571 differentially expressed operons, 122 operons had unknown functions. Of these, 87 were downregulated and 35 were upregulated. 


\subsection{Transcriptional Profile of Salmonella within the Acanthamoebae Phagosomes}

In intracellular Salmonella, most of the operons with upregulated expression belonged to bacterial chemotaxis and flagellar assembly, LPS biosynthesis, glycerophospholipid metabolism, amino acid biosynthesis, and glyoxylate and dicarboxylate metabolism, according to KEGG (Kyoto Encyclopedia of Genes and Genomes) (Figure 1). Expression of the operons belonging to the tricarboxylic acid cycle (TCA), fructose and mannose metabolism, pyruvate and butanoate metabolism, oxidative phosphorylation, and phosphotransferase system was downregulated (Figure 1).

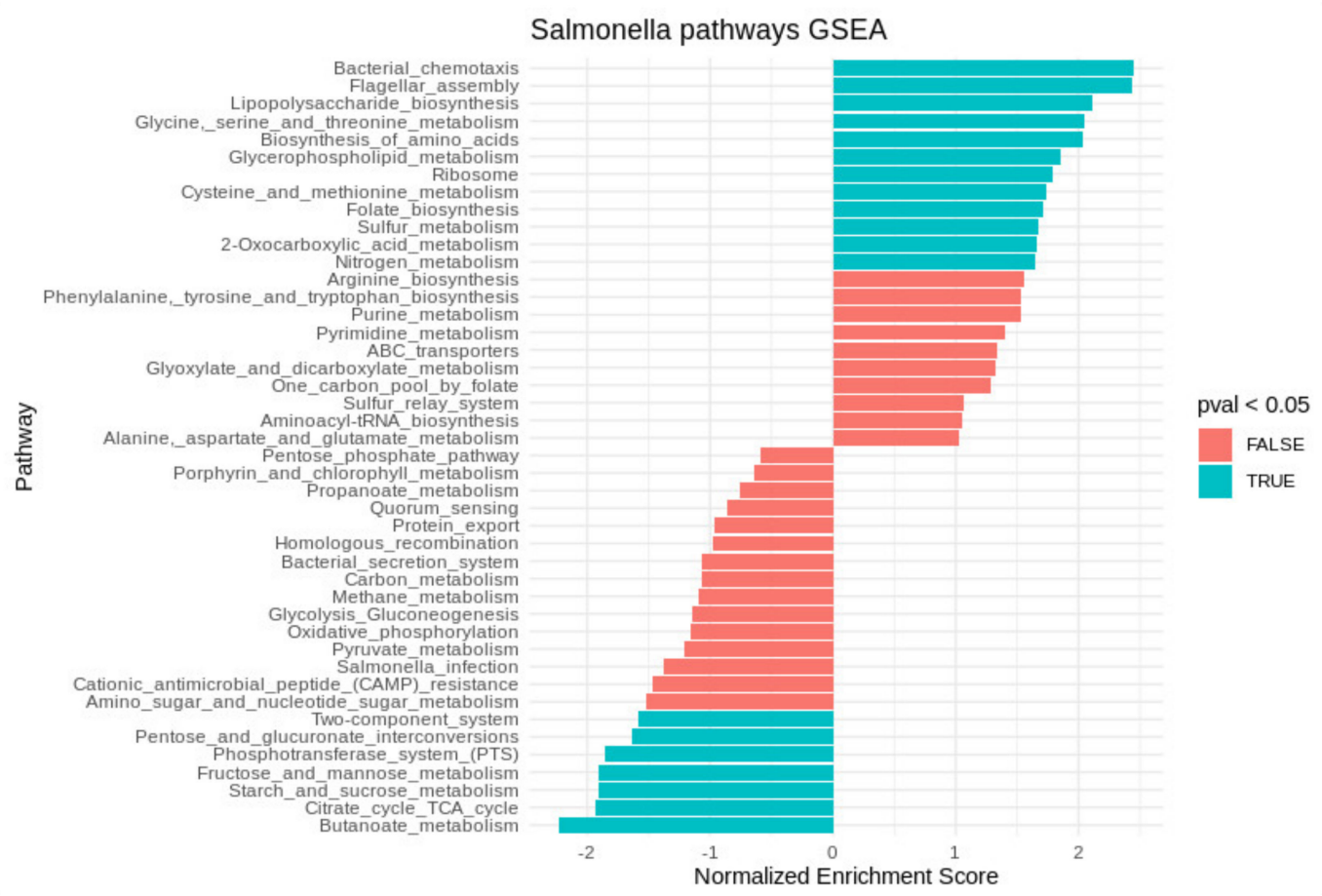

Figure 1. Gene set enrichment analysis performed using the fgsea package. Positive (normalized) enrichment scores indicate upregulation of genes in the pathway in Salmonella within Acanthamoeba. Negative (normalized) enrichment scores indicate downregulation of genes in the pathway in Salmonella within Acanthamoeba. Operon pathway annotation was determined against the KEGG database.

Numerous operons belonging to "carbohydrate transport and metabolism" from COG (Cluster of Orthologous Groups) had increased expression within Acanthamoeba. Expression of operons involved in intracellular trafficking processes, secretion, vesicular transport, replication, recombination, and repair were significantly upregulated. Expression of genes controlling translation, ribosomal structure and biogenesis, posttranslational modification, protein turnover, chaperone synthesis, and energy production and conversion were downregulated.

\subsection{Expression of Genes Associated with Iron Uptake and Stress Response}

Expression of the SPI-1-encoded operon $\operatorname{sit} A B C D$ responsible for iron uptake was upregulated within Acanthamoeba (Table 1) as were the operons not located in the SPI regions. Hence, the operons sufABCDSE, fep $A E$, entS, entD, fepB, and $y b d A$ were activated $>2 \times$ within Acanthamoeba compared to those in the control libraries (Table 1), as well as the aluminum-inducible gene STM14_2833 (ais), which is activated under iron depletion [25]. However, expression of several operons involved in iron uptake were downregulated in the Salmonella within Acanthamoeba SCV, including operons of iron transporter $f e o A B$, the fumarate reductase flavoprotein $\operatorname{fr} d A B C D$, and the iron storage and detoxification protein bfr. 
Table 1. Selected operons and genes that were differentially expressed in Salmonella within Acanthamoeba.

\begin{tabular}{|c|c|c|}
\hline Operon & $\log _{2}$ Fold Change & Description \\
\hline \multicolumn{3}{|c|}{ Metal uptake } \\
\hline sufABCDSE & 2.76 & iron-sulfur cluster assembly \\
\hline$f h u$ & 2.65 & uptake of ferric hydroxamate \\
\hline ent & 3.55 & enterobactin exporter \\
\hline fep & 1.23 & $\begin{array}{l}\text { ferric enterobactin transport } \\
\text { protein }\end{array}$ \\
\hline fes & 2.73 & ferric enterobactin esterase \\
\hline $\operatorname{cor} A$ & 1.65 & $\begin{array}{c}\text { magnesium/nickel/cobalt } \\
\text { transporter }\end{array}$ \\
\hline \multicolumn{3}{|c|}{ Oxidative stress response } \\
\hline $\operatorname{ahpCF}$ & 3.67 & alkyl hydroperoxide reductase \\
\hline $\operatorname{grx} A$ & 2.40 & glutaredoxin A \\
\hline katG & 1.89 & hydroperoxidase \\
\hline $\operatorname{sod} A$ & 2.18 & $\begin{array}{l}\text { superoxide dismutase } \\
\text { (manganese) }\end{array}$ \\
\hline $\operatorname{sodB}$ & -3.20 & superoxide dismutase (iron) \\
\hline \multicolumn{3}{|c|}{ SPI-1 } \\
\hline sit $A B C D$ & 1.13 & manganese/iron transport \\
\hline prgKJIH-org $A B C$ & 1.27 & needle complex \\
\hline hilA-iagB & 1.56 & invasion protein \\
\hline spaPOL-invJI & 2.17 & needle complex \\
\hline invABEFG & 1.20 & invasion complex \\
\hline$i n v H$ & 2.46 & $\begin{array}{l}\text { involved in the synthesis of } \\
\text { the type III secretion system }\end{array}$ \\
\hline \multicolumn{3}{|c|}{ SPI-2 } \\
\hline$s s a B C D E$ & -2.36 & $\begin{array}{c}\text { type III secretion system } \\
\text { apparatus }\end{array}$ \\
\hline sseABCDE & -2.47 & $\begin{array}{l}\text { translocation machinery } \\
\text { components }\end{array}$ \\
\hline ssaGHIJ & -1.88 & type III secretion system \\
\hline$s s a M V N$ & -2.66 & type III secretion system \\
\hline ssaRSTU & -1.88 & type III secretion system \\
\hline$y d h C$ & 1.68 & inner membrane transport \\
\hline \multicolumn{3}{|c|}{ Motility and chemotaxis } \\
\hline$f l h$ & 1.70 & flagellar biosynthesis \\
\hline$f l i$ & 1.48 & flagellar biosynthesis \\
\hline mot & 1.70 & flagellar motor protein \\
\hline che & 1.70 & chemotaxis \\
\hline
\end{tabular}

Here, several genes involved in zinc homeostasis were differentially expressed. The genes of zinc transporter ATPase (zntA), the zinc-responsive two-component regulator $(z r a S R)$, and the putative zinc-dependent peptidase (yhjJ) were upregulated, whereas 
yggG (zinc-dependent protease) and zraP (zraSR two-component system repressor) were downregulated.

Expression of genes encoding oxidative stress response glutaredoxin ( $g r x A)$, the hydroperoxidase ( $k a t G)$, the putative oxidoreductases (STM14_4644, STM14_4645, and yieEF), the superoxide dismutase $\operatorname{sod} A$, the putative thiol-alkyl hydroperoxide reductase (STM14_0476), the alkyl hydroperoxide reductase ( $a h p C F)$, and the putative irondependent peroxidases (STM14_3004 and STM14_3005) was upregulated within Acanthamoeba (Table 1). In contrast, expression of the superoxide dismutases genes $\operatorname{sod} B$ and sodC and the oxidoreductase gene STM14_2022 was downregulated. Furthermore, the peroxidase genes had increased expression in the Salmonella within Acanthamoeba. The expression of $a h p C F$ was $25 \times$ higher within Acanthamoeba than the control culture (Table 1).

In the Salmonella within Acanthamoeba, expression of the genes encoding heat shock proteins (dnaKJ, ibpAB, hslJ, and STM14_1509), the small regulatory RNA RprA, the universal stress proteins ( $u s p B$ and $u s p E$ ), and cold shock protein ( $\operatorname{sp} E$ ) was downregulated. Expression of yjeY, which encodes carbon starvation response, was downregulated within Acanthamoeba.

There were no significant differences between treatments in terms of their global expression regulator rpoS activity levels. The same was true for mammalian phagocytes [15-17].

\subsection{Expression of Genes Associated with Virulence}

Most of the genes responsible for virulence in Salmonella are located in the SPI regions. Of these, SPI-1 and SPI-2 are the largest. SPI-1 is considered critical for epithelial cell invasion. Within Acanthamoeba, most Salmonella operons, including those encoding T3SS-1, had increased expression. The genes such as inv $H$, inv $A B E F G$, $\operatorname{prg} K J I H$, and $\operatorname{org} A B C$ controlling Salmonella invasion in host cells and sptP involved in post-infection host cytoskeleton recovery [26] were significantly upregulated in the Salmonella within Acanthamoeba (Table 1). Expression of sopE encoding the SopE effector protein translocated by the SPI-1 T3SS was also upregulated in the internalized Salmonella. The SPI-1-encoded operon spaSRQ comprises needle complex genes that were significantly downregulated in the Salmonella within Acanthamoeba.

Expression of most SPI-2 operons including $s s a B C D E$, sse $A B C D E, s s c A$, ssaMVN, and ssaRSTU were downregulated in the Salmonella within Acanthamoeba (Table 1). SPI-5 encoded genes pip $C$ and sopB were upregulated within Acanthamoeba. These genes have been shown to be crucial for invasion in host cells [27].

Six virulence plasmid operons involved in conjugative transfer including traJYALEKBP, $\operatorname{trbD}$, and traV had downregulated expression in the Salmonella within Acanthamoeba.

Several genes located on pathogenicity islands and involved in infection had upregulated expression in the Salmonella within the Acanthamoeba SCV; for example, the expression of $y b d A$ encoding the enterobactin (siderophore) exporter (EntS) was $>16 \times$ higher than it was in the control libraries. Certain genes involved in multidrug resistance such as the efflux pump operon $m d l A B$ were highly upregulated in the Salmonella within Acanthamoeba. Expression of lysozyme inhibitor gene mliC was downregulated in the Salmonella within the amoebae.

Expression of the genes $b s s R$ and bss $S$ encoding biofilm regulatory proteins and $b s m A$ encoding biofilm peroxide resistance protein were downregulated within Acanthamoeba.

Expression of the operons fliLMNOPQR, fliDST, and flhCD participating in flagellar biosynthesis and mot $A B$ and che $A W M$ responsible for flagellar motor and chemotaxis were upregulated within Acanthamoeba (Table 1).

Transcription of eleven genes (Table S4) in Salmonella and Salmonella-Acanthamoeba co-cultures was examined by qRT-PCR in another series of experiments. Eight genes, responsible for SPI-1, oxidative stress response ( $\mathrm{rr} x A$, $k a t G)$, iron uptake, and glucose-1phosphatase were found to express in the same manner as it was observed in RNA-Seq analysis (Figure 2). Both Cappable-Seq and qRT-PCR data demonstrated that iron uptake and oxidative stress response genes were upregulated, while glucose-1-phosphatase gene 
was downregulated in Salmonella within Acanthamoeba compared to control Salmonella culture. Expression of $\operatorname{sip} C$ and sit $A$ (both SPI-1 encoded) induced according to the qRTPCR analysis, whereas expression of another gene encoded in SPI-1 $(\mathrm{prgH})$ did not change. Besides, expression of SPI-2 encoded gene sseC was unaltered in contrast to downregulation found with RNA-Seq. Malate synthase gene $(a c e B)$ involved in GS cycle was significantly upregulated in SA samples based on the qRT-PCR data, which differs from the CappableSeq results (remains unchanged).

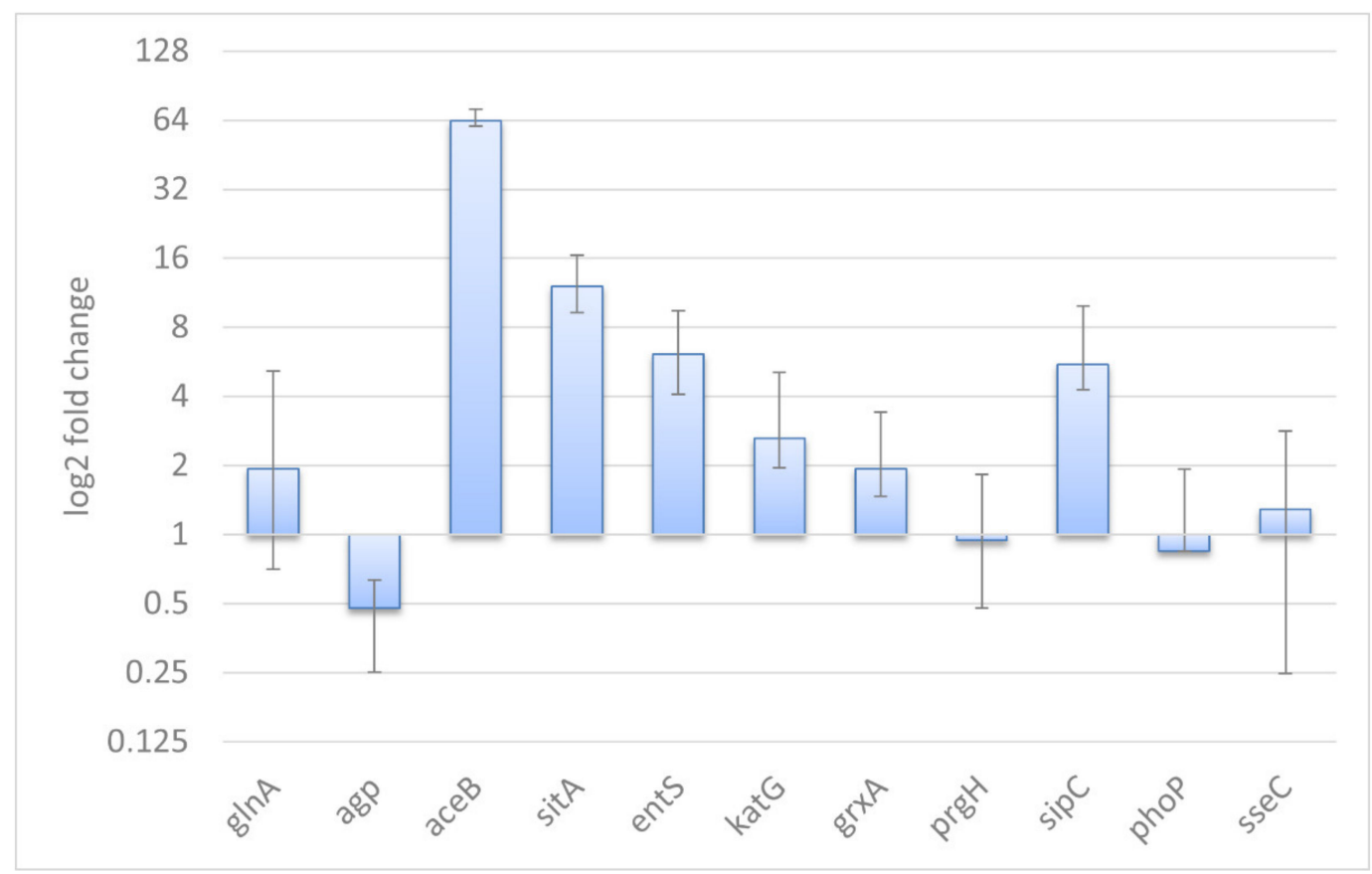

Figure 2. Relative expression levels of selected genes in S. Typhimurium. A value of 1 indicates no detectable difference in expression between intracellular Salmonella and control. Values $>1$ indicate higher expression in intracellular bacteria and values $<1$ indicate higher expression in control bacteria. Expression values normalized to the reference gene expression (rpoD).

\section{Discussion}

\subsection{Metabolic Pathways of Salmonella within Acanthamoeba SCV}

Here, the TCA cycle, glycolysis, and the pentose phosphate pathway were downregulated in the Salmonella within Acanthamoeba (Figure 1) compared to those in the model macrophage and epithelial cell infections $[15,17]$. Glucose is considered a main carbon source during Salmonella infection [28]. Glucose, gluconate, and lactate are accessible to Salmonella inside mammalian phagocytes and are involved in the TCA cycle and glycolysis $[17,29]$. However, several studies showed that glyoxylate shunt (GS) is necessary for certain stages of Salmonella infection [30,31]. The glyoxylate cycle-related genes were upregulated in the Salmonella inside the Acanthamoeba SCV (Figure 3). The GS enables an organism to utilize acetate and fatty acids as carbon sources under physiological conditions requiring gluconeogenesis [32]. Acanthamoeba SCV may contain less glucose than mammalian macrophage SCV. Therefore, fast consumption of glucose in the protozoan SCV could trigger the switch from TCA and glycolysis to the GS. Downregulation of glycolysis gene expression, as well as upregulation of glyoxylate cycle genes was also confirmed by the qRT-PCR. 


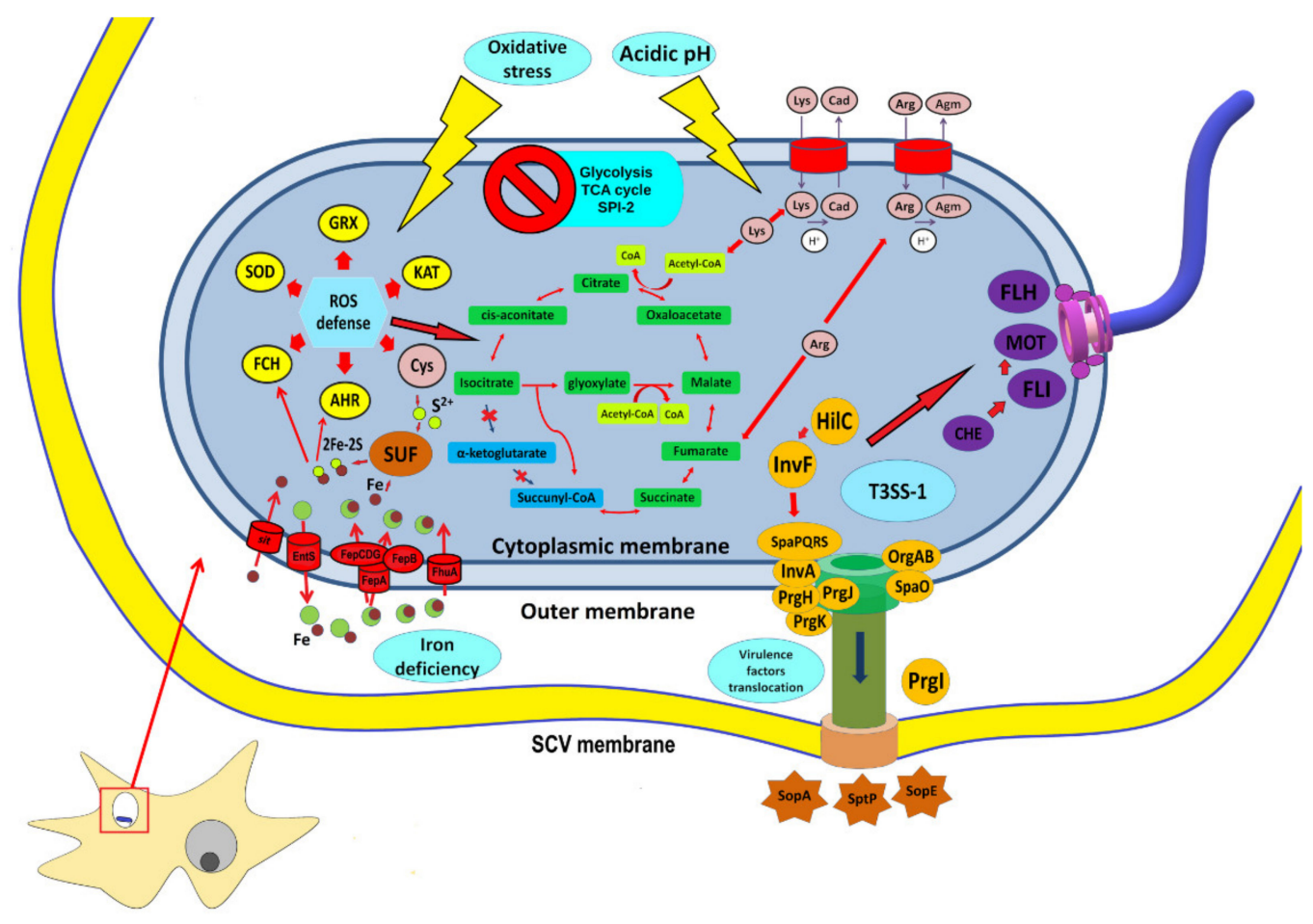

Figure 3. Reconstruction of the main metabolic and functional systems of $S$. Typhimurium responsible for $A$. castellanii infection. Enzymes involved in oxidative stress response are highlighted in yellow. Oxidoreductases included in Fe-S clusters (2Fe-2S) activating iron uptake system are in red (ent, fhu, and fep). Fe-S cluster assembly systems (SUF) are in brown. Glyoxylate shunt (GS; green) was shifted to the tricarboxylic acid (TCA) cycle and induced by reactive oxygen species (ROS). Low pH activates arginine (Arg) and lysine (Lys) metabolism (pink). Upregulation of SPI-1 genes (orange), flagellar apparatus (purple), and chemotaxis (purple) operons indicate that Salmonella penetrates protozoan cells. GRX, glutaredoxin 1; KAT, catalase G; AHR, alkyl hydroperoxide reductase; FCH, ferrochelatase; SOD, superoxide dismutase; SUF, Fe-S cluster assembly; Cys, cysteine; Lys, lysine; Cad, cadaverine; Arg, arginine; Agm, agmatine; FLH, flagellar assembly proteins flh; MOT, stator proteins MotAB; FLI, flagellar assembly proteins fli; $\mathrm{CHE}$, chemotaxis.

GS may also be implicated in Salmonella pathogenesis and oxidative stress response [32]. RNS formed in the phagosomes inhibit oxidative phosphorylation and TCA cycle genes [33]. Nitric oxide in phagosomes activates the iron citrate efflux transporter (IctE) that ferries citrate-chelated iron out of the cell [34]. Citrate is an intermediate metabolite in the GS and maintains iron homeostasis in Salmonella by chelating this metal [35]. Iron is an essential cofactor for several enzymes. However, excess iron may cause cell damage and is normally chelated by citrate [35]. Thus, GS increases the citrate pool required for iron neutralization and extracellular transport. Besides, in Salmonella, citrate export arrests growth and enhances oxidative stress resistance $[34,35]$.

Expression of several operons encoding amino acid biosynthesis was upregulated in the Salmonella within Acanthamoeba. The cysteine, arginine, and lysine metabolic pathways were significantly enriched. Intermediates of the pathways may be involved in GS (Figure 3). Several amino acids play important roles in the adaptation of Salmonella to stress conditions. For example, cysteine biosynthesis was induced in Salmonella subjected to oxidative stress [36]. The arginine-dependent acid tolerance pathway was activated in Salmonella within Tetrahymena phagosomes [14]. Lysine is produced in response to acid stress through activation of the cad $A B$ operon that provides lysine decarboxylation and cadaverine formation. Cadaverine undergoes protonation in acidic environments and raises the external $\mathrm{pH}$ [37]. Here, the arginine and lysine pathways might have been activated in response to the acidic environment of the Acanthamoeba SCV, whereas the cysteine pathway was upregulated in response to oxidative stress. Obviously, Salmonella engulfed by mammalian macrophages use similar protective pathways to acid stress like 
those in Acanthamoeba SCV, inducing cysteine and arginine biosynthesis [15,17]. In contrast, within epithelial cells, Salmonella downregulated expression of the cadAB operon [15].

LPS and its components (lipid A, O-antigen, core) are considered crucial for Salmonella virulence, macrophage survival, and acid stress response [38,39]. Upregulation of the operons involved in LPS and glycerophospholipid biosynthesis was observed in the Salmonella within Acanthamoeba. Similar findings were reported for Salmonella in Dictyostelium discoideum [12] and humanized mice [39]. Thus, the activation of LPS, glycerophospholipid, arginine, and lysine biosynthesis constitute the complex response of Salmonella to acidic conditions' survival in protozoan and mammalian SCV.

\subsection{Iron Uptake and Oxidative Stress}

Iron is an essential growth factor for pathogenic bacteria [40] and a signaling element regulating virulence-associated genes [41].

Expression of the main operon associated with iron consumption (sit $A B C D$ ) was upregulated in Salmonella within Acanthamoeba (Figure 3). A similar finding was reported for Salmonella phagocytosed by mammalian cells [15,17]. Moreover, in the Salmonella of the present study, iron uptake may have been mediated by additional ways. Thus, we observed the activation of the siderophore enterobactin entS and the $\mathrm{Fe}^{3+}$-catecholate (fep $A$, $f e p B$, and $f e p C D G$ ) and $\mathrm{Fe}^{3+}$-hydroxamate (fhuACDB) transporters (Figure 3). The iron acquisition systems are activated under iron-depleted conditions [42], and are essential for virulence of Salmonella and its survival in macrophages $[43,44]$. Thus, Salmonella within the Acanthamoeba SCV may undergo significant iron deficiency.

Iron determines the activity of certain regulatory and virulence genes [41,42]. Expression of genes encoding T3SS, flagellin, cold-shock protein ( $\operatorname{csp} E)$, enterobactin transporter (entS), and other regulatory genes were upregulated under iron-depleted conditions [42]. Here, we observed similar changes in the transcriptome of Salmonella in the Acanthamoeba SCV presented with activation of flagellin biosynthesis and T3SS (Figure 3).

Iron is vital in the functioning of oxidoreductases that neutralize ROS such as hydrogen peroxide, superoxide, and hydroxyl radicals [45]. Both mammalian macrophages and D. discoideum amoeba utilize NADPH oxidase to generate bactericidal superoxide [46]. Phagocytosed bacteria respond to oxidative stress by producing catalases, peroxiredoxins, and superoxide dismutases that neutralize ROS [47]. In the present study, expression of several oxidoreductase genes was upregulated in response to oxidative stress, including $\operatorname{grx} A, k a t G$, sodA (Mn-cofactored superoxide dismutase), and ahpCF (alkyl hydroperoxide reductase system). The grxA and kat G genes were also activated in Salmonella phagocytosed by Tetrahymena [14] and macrophages [17]. In contrast, expression of $\operatorname{sodB}$ and soxR was downregulated in Salmonella inside Acanthamoeba. The sodA senses hydrogen peroxide whereas sodB and soxR detect superoxide-generating compounds [48]. Hence, $\mathrm{H}_{2} \mathrm{O}_{2}$ might be the main ROS produced by the amoebae. In addition, enzyme encoded by kat $G$ is able to inactivate RNS due to peroxynitritase activity [49].

Another mechanism of bacterial killing is based on $\mathrm{Zn}^{2+}$ and $\mathrm{Cu}^{2+}$ accumulation in phagosomes of mammals [50,51] and protozoa [52]. $\mathrm{Zn}^{2+}$ and $\mathrm{Cu}^{2+}$ attack Fe-S clusters vital to bacterial survival [52]. In the present study, the zinc-dependent, two-component system ZraRS responding to envelope stress was activated [53]. Perhaps, A. castellanii accumulate $\mathrm{Zn}^{2+}$ in its SCV to kill phagocytosed bacteria. Fe-S cluster-containing proteins are involved in many essential cellular processes, including overcoming the adverse effects of oxidative stress [54]. In Salmonella, Fe-S cluster assembly and delivery are controlled mainly by iron sulfur cluster (ISC) and sulfur mobilization (SUF) operons. The isc operon might regulate the housekeeping Fe-S cluster assembly system, whereas the suf operon controls Fe-S cluster biogenesis under iron starvation and oxidative stress [55]. Here, the suf operon was upregulated in phagocytosed Salmonella. Thus, upregulation of several genes encoding antioxidant defense factors in response to oxidative stress inside the amoebae protects Salmonella from protozoan bactericidal systems and potentiates bacterial virulence. Within Acanthamoeba SCV, Salmonella induces iron uptake systems participating in oxidative 
stress response, augmenting bacterial virulence, and establishing and maintaining iron homeostasis. Iron uptake activation may enhance bacterial resistance to the host $\mathrm{Zn}$ dependent killing mechanism by increasing the iron concentration.

In this study, there was no upregulation of the Salmonella genes (phoPQ, rpoE, soxS, and $o x y R$ ) encoding factors responding to low osmolarity, low $\mathrm{Ca}^{2+}$ concentrations, or acidic $\mathrm{pH}$. In contrast, the aforementioned genes were upregulated in macrophage SCV [17]. Expression of genes, encoding heat shock (ibp $A B, d n a K J)$, cold shock $(\operatorname{csp} E)$, osmoregulation $(o m p W)$, and universal stress response ( $u s p B$ and $u s p E$ ) were significantly downregulated in /the Salmonella within Acanthamoeba. Moreover, we noted the activation of the cpxP transcriptional repressor of the two-component system cpxRA governing envelope stress response [56]. Therefore, the conditions inside Acanthamoeba SCV seem to be more advantageous to Salmonella survival than those inside macrophage SCV. In Acanthamoeba SCV, Salmonella is subjected mainly to oxidative stress, whereas the bacterium would be exposed to numerous simultaneous stressors in macrophages.

\subsection{Virulence and Motility}

Recent studies reported the induction of several virulence genes in Salmonella interacting with protozoa $[12,14,21]$. The involvement of these genes in mammalian epithelial cell, fibroblast, and macrophage infection has been previously described $[15,17,20]$. The genes responsible for the interaction between the bacterium and host cells are combined into clusters collectively named SPI $[28,57]$. Here, we observed the upregulation of the SPI-1-encoded virulence factors inv $H$, inv $A B E F G$, $\operatorname{prg} K J I H$, and $\operatorname{org} A B C$ in Salmonella inside Acanthamoeba SCV. Induction of T3SS-1 encoded by SPI-1 is required to enable Salmonella to invade epithelial cells [58]. Earlier reports suggest that Salmonella invade Acanthamoeba by a mechanism similar to that for epithelial cells $[15,22]$.

In the present study, in intracellular Salmonella, several genes encoding virulence factors in non-SPI regions were upregulated such as $s r f C, y b j X, h u p A$, and $m s g A$ encoding the putative virulence effector, VirK-like, HU DNA-binding, and virulence MsgA proteins, respectively. These proteins are involved in internalization and protection of Salmonella in epithelial cells $[59,60]$ and macrophages [61].

It should be noted that in phagocytosed Salmonella, expression of SPI-2 genes associated with long-term persistence such as ssaBCDE, sse $A B C D E$, sscA, ssaMVN, and ssaRSTU remain at low level. SPI-2 is activated in response to $\mathrm{PO}_{4}{ }^{3-}, \mathrm{Mg}^{2+}$, and $\mathrm{Ca}^{2+}$ deficiency, low $\mathrm{pH}$ and osmolarity within epithelial cells, macrophages $[15,17]$, Tetrahymena phagosomes [14], and Acanthamoeba SCV [22]. However, Karlinsey et al. [39] showed that SPI-2 genes in $S$. Typhi were not required for mouse and macrophage survival during the early infection stages. Besides, it has been clearly shown on the $S$. Typhimurium infection of fibroblasts [20] that SPI-2 is not upregulated during first two h p.i. However, non-activated SPI-2-encoded genes suggest that Salmonella in Acanthamoeba SCV were unaffected by acid $\mathrm{pH}$, low osmolarity, and $\mathrm{Mg}^{2+}, \mathrm{Ca}^{2+}$, and $\mathrm{PO}_{4}{ }^{3-}$ deficiency at early stage of infection. The latter two ions are major SPI-2 activation factors [62].

Free-living Salmonella upregulate genes governing flagellar assembly and flagellin synthesis in conditions conducive to active movement and adhesion. These genes are downregulated in macrophages and fibroblasts [20]; however, for unknown reasons, they are upregulated in epithelial cells at the early stage of infection [15]. Here, we detected induction of the operons controlling flagellum biosynthesis (fliLMNOPQR, fliDST, and flh $C D)$, flagellar motor (mot $A B)$, and chemotaxis (cheAWM) in Salmonella within Acanthamoeba. Moreover, we found upregulation of the $t d c A$ transcriptional activator in the $t d c$ operon governing threonine and serine transport and metabolism during anaerobic growth [63]. The requirement of threonine and serine for flagellin biosynthesis and virulence was demonstrated via Salmonella $\Delta t d c A$ mutants, which were less virulent than the WT in mice $[63,64]$. 


\subsection{Validation of the RNA-Seq Results and General Remarks}

A new series of experiments was conducted with the same conditions for biological validation of the RNA-Seq results with qRT-PCR. Although, most genes demonstrated the same expression patterns, we should note a few discrepancies in the Cappable-Seq and qRT-PCR results. Particularly, SPI-1 encoded $\mathrm{prgH}$ showed unchanged expression in qRT-PCR, while it was upregulated in Cappable-Seq. Nevertheless, other two SPI-1 encoded genes, $\operatorname{sip} C$ and $\operatorname{sit} A$, were upregulated significantly according to the qRT-PCR data that supports whole SPI-1 activation. Such contradictory trends in gene expression are in good agreement with non-simultaneous activation of SPI-1 genes reported by Ibarra et al. 2010 [65]. Expression of SPI-2 encoded sseC was unchanged based on the qRT-PCR analysis, while it was downregulated according to the Cappable-Seq data. This inconsistency can be related to the fact that different series of experiments have been carried out for RNA-Seq and qRT-PCR analyses. Anyway, no induction of $s s e C$, revealed based on both methods, is in good agreement that expression of SPI-2 was unchanged at early infection times $[19,20]$. Expression of $a c e B$ remained unchanged according to the RNA-Seq data, while qRT-PCR demonstrated significant upregulation of this gene, which is in good agreement with RNASeq data, demonstrating activation of glyoxylate cycle accompanied with high enrichment score of this metabolic pathway. In addition, expression of $a c e A B$ is known to be regulated independently from other GS cycle genes [66]. Moreover, the samples used for qRT-PCR were distinct to the samples used for RNA-Seq and that could be a source of the discrepancy seen in the validation tests. Except for those three genes, we found a good coincidence in the expression patterns for other eight genes based on the RNA-Seq and qRT-PCR data.

The transcriptome of the Salmonella in A. castellanii SCV significantly differed from those of the Salmonella in other protozoa [14,22] and mammalian phagocytes [15,17]. In fact, viability visibly differs among various types of phagocytic cell infected by the same bacterium. For example, S. Typhimurium is not cytotoxic to Tetrahymena, whereas it induces massive apoptosis-like death in Acanthamoeba rhyzodes at $24 \mathrm{~h}$ post-infection [14,22]. Transcriptomic data showed significant differences in the gene expression in Salmonella within protozoa of different taxa, e.g., far more SPI-1 genes were activated within $A$. rhysodes than Tetrahymena [14,22]. Genes controlling translation, ribosomal structure, and biogenesis were induced at $3 \mathrm{~h}$ post-infection within Tetrahymena but at $8 \mathrm{~h}$ post-infection in amoebae. O-antigen and T6SS are required for Salmonella to survive inside D. discoideum [12]. Expression of SPI-2 genes was unchanged in Salmonella within A. castellanii, but upregulated in the bacteria within $A$. rhyzodes. In contrast, the genes encoding flagellum biosynthesis were upregulated in A. castellanii but downregulated in A. rhyzodes [22]. These differences might be explained by dissimilar infection time points $(5 \mathrm{~h}$ post-inoculation in $A$. rhyzodes but $2 \mathrm{~h}$ post-inoculation in A. castellanii) and different Salmonella strains (S. choleraesuis SC-B67 vs. S. Typhimurium 14028S). Obviously, during the long evolutionary history of the interactions between Salmonella and phagocytes, the bacteria could develop various mechanisms to ensure their survival and persistence in protozoa, serving as a "Trojan horses" for bacterial pathogens.

A limitation of our study is the evaluation of Salmonella transcriptome only at an early stage of Acanthamoeba infection. This stage of infection allows to disclose specific expression patterns that support survival of Salmonella adapting to the Acanthamoeba SCV conditions. However, Salmonella can change their expression patterns at a late stage of Acanthamoeba infection, which is accompanied by multiplication of the bacteria within SCV and host cell death [22]. Therefore, to understand molecular mechanisms of prolonged Salmonella persistence in protozoan cells, the study of a time-dependent transcriptional adaptation is required. However, such study may be complicated by massive apoptosis-like cell death induced by Salmonella at later stages of the infection [22].

In this study, we evaluated the response of Salmonella to conditions within Acanthamoeba at the early stage of infection. The transcriptional profile of Salmonella in Acanthamoeba had certain similarities to those for Salmonella in macrophages, epithelial cells, and fibroblasts (Figure 4). 


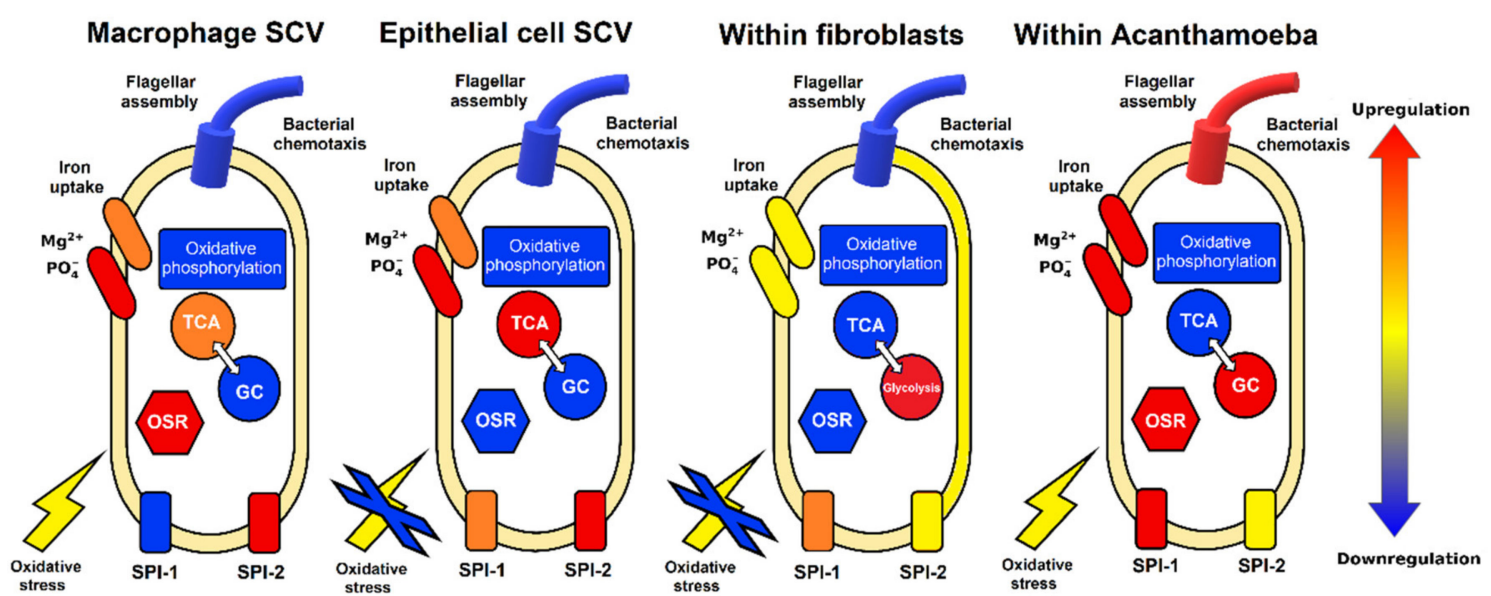

Figure 4. Response of $S$. Typhimurium to intracellular environment of macrophages [15,17], epithelial cells [15], fibroblasts [20], and A. castellanii (this study). Each symbol represents functionally related proteins. Colors reflect the expression levels of appropriate genes under each condition. Oxidative stress response, OSR; Glyoxylate cycle, GC; tricarboxylic acid cycle, TCA.

Salmonella are exposed to ROS in both macrophages and Acanthamoeba, but not in epithelial cells and fibroblasts. Salmonella are iron-deficient in both macrophages and Acanthamoeba. In response to intracellular conditions, the bacteria induce iron transport, oxidoreductase systems, and LPS biosynthesis. The Acanthamoeba model has similarities with the fibroblast infection model [20] by no-induction of SPI-2 and TCA cycle downregulation. In contrast to the macrophage model, SPI-1 expression was upregulated in the Acanthamoeba model, in epithelial cells and fibroblasts. Unlike known bacterial infection models in macrophages and epithelial cells, Salmonella in Acanthamoeba SCV at $2 \mathrm{~h}$ p.i. presented with specific patterns of gene expression, including switching from the TCA cycle and oxidative phosphorylation to the GS, activation of chemotaxis system, and flagellar apparatus biosynthesis (Figure 4). The gene expression profile of Salmonella in Acanthamoeba may reflect the symbiotic association between these organisms. The results of this study provided theoretical and empirical evidence of Salmonella-specific metabolic and virulence patterns for intracellular survival in unicellular and multicellular eukaryotes.

\section{Materials and Methods}

\subsection{Strains}

Salmonella enterica subspecies enterica serovar Typhimurium strain ATCC ${ }^{\circledR} 14028$ was obtained from the American Type Culture Collection (ATCC, Manassas, VA, USA) grown in Luria broth at $37^{\circ} \mathrm{C}$ without antibiotics.

Axenic culture of free-living Acanthamoeba castellanii Neff strain ATCC $^{\circledR}$ 30010TM was obtained from the American Type Culture Collection (ATCC, Manassas, VA, USA). Trophozoites were cultivated in $10 \mathrm{~mL}$ of peptone-yeast extract-glucose medium (PYG; $2 \%$ $(w / v)$ proteose peptone, $0.1 \%(w / v)$ yeast extract, $4 \mathrm{mM} \mathrm{MgSO}_{4} \times 7 \mathrm{H}_{2} \mathrm{O}, 0.5 \mathrm{mM} \mathrm{CaCl}_{2}$, $0.1 \mathrm{M}$ sodium citrate $\times 2 \mathrm{H}_{2} \mathrm{O}, 2.5 \mathrm{mM} \mathrm{Na} 2 \mathrm{HPO}_{4} \times 7 \mathrm{H}_{2} \mathrm{O}, 2.5 \mathrm{mM} \mathrm{KH} \mathrm{PO}_{4}, 0.05 \mathrm{mM}$ $\mathrm{Fe}\left(\mathrm{NH}_{4}\right)_{2}\left(\mathrm{SO}_{4}\right)_{2} \times 12 \mathrm{H}_{2} \mathrm{O}$, and $0.1 \mathrm{M}$ glucose; $\mathrm{pH}$ 7.0) in sterile 50-mL conical tubes (Eppendorf AG, Hamburg, Germany) at $25^{\circ} \mathrm{C}$. Reseeding was performed every $7 \mathrm{~d}$.

\subsection{Co-Culture Conditions}

A. castellanii axenic culture was grown for $5 \mathrm{~d}$ in PYG medium to a density of $4-5 \times 10^{5}$ cells $/ \mathrm{mL}$. The cells were centrifuged at $800 \times g$ for $5 \mathrm{~min}$ at $25{ }^{\circ} \mathrm{C}$, washed twice with Page's Amoeba Saline (PAS; $1.6 \mathrm{mM} \mathrm{MgSO} 4 \times 7 \mathrm{H}_{2} \mathrm{O}, 0.4 \mathrm{mM} \mathrm{CaCl}_{2}, 0.1 \%$ sodium citrate $\times 2 \mathrm{H}_{2} \mathrm{O}, 2.5 \mathrm{mM} \mathrm{NaH}_{2} \mathrm{PO}_{4}, 2.5 \mathrm{mM} \mathrm{K}_{2} \mathrm{HPO}_{4}$, and $0.05 \mathrm{mM} \mathrm{Fe}\left(\mathrm{NH}_{4}\right)_{2}\left(\mathrm{SO}_{4}\right)_{2}$ $\times 12 \mathrm{H}_{2} \mathrm{O}$ ), and suspended in $10 \mathrm{~mL}$ fresh PAS. The washed cells were incubated for $1 \mathrm{~h}$ at $25{ }^{\circ} \mathrm{C}$ until they were adherent. 
S. Typhimurium was grown in LB medium at $37^{\circ} \mathrm{C}$ without shaking until the late logarithmic phase. The cells were collected by centrifugation at $3000 \times g$ for 5 min at $25^{\circ} \mathrm{C}$, washed twice with PAS, suspended in fresh PAS, and seeded at $25^{\circ} \mathrm{C}$ for $30 \mathrm{~min}$ until they adapted to the new growth conditions. The Salmonella cells were added to the Acanthamoeba culture in sterile PAS at a 100:1 bacterium:amoeba ratio. The co-culture was incubated until most of the bacteria had been ingested by the Acanthamoeba. At $1 \mathrm{~h}$ from the start of co-incubation, the suspension was centrifuged at $800 \times g$ for $10 \mathrm{~min}$ at $25^{\circ} \mathrm{C}$. Supernatants were discarded (for $1 \mathrm{~min}$ ). Then three cycles of washing were carried out. Each cycle included next steps: pellets were resuspended with gentle shaking in sterile PAS for $1 \mathrm{~min}$ and incubated for $4 \mathrm{~min}$ at $25^{\circ} \mathrm{C}$; infected amoeba cells were centrifuged at $800 \times g$ for $10 \mathrm{~min}$ at $25^{\circ} \mathrm{C}$; supernatants were discarded (for $1 \mathrm{~min}$ ). Final pellets were fixed in $1 \mathrm{~mL}$ ExtractRNA reagent (Evrogen, Moscow, Russia) exactly in $2 \mathrm{~h}$ from the start point of the infection.

Confocal microscopy confirmed that after washing, most Acanthamoeba cells contained visible Salmonella cells inside the cytoplasm (Figure 5). To control extracellular Salmonella cells, the supernatants after the last washing were examined with LB plating and PCR. One hundred $\mu \mathrm{L}$ of supernatants were inoculated on the LB plates and spread with a sterile glass spatula. After incubation at $37^{\circ} \mathrm{C}$ for $72 \mathrm{~h}, \mathrm{CFU}$ were not detected. Control of extracellular Salmonella was also performed using PCR (Figure S3). For PCR, the supernatant after each centrifugation was collected in a sterile $1.5 \mathrm{~mL}$ tube, then $100 \mu \mathrm{L}$ was transferred to a new sterile $1.5 \mathrm{~mL}$ tube. Lysing matrix E (Zymo Research, Irvine, CA, USA) in equal volume was added, and the samples were homogenized in a Tissue Lyser LT (QIAGEN, Hilden, Germany) for $5 \mathrm{~min}$ at $50 \mathrm{~Hz}$. Lysates were inactivated by heating at $95^{\circ} \mathrm{C}$ for $5 \mathrm{~min}$. PCR was conducted using a thermocycler (T100 Thermal Cycler, Bio-Rad, Hercules, CA, USA) in a $25 \mu \mathrm{L}$ reaction mixture containing $3.75 \mu \mathrm{L}$ of $5 \times$ Q5 reaction buffer (New England Biolabs, Ipswich, MA, USA), $1.25 \mu \mathrm{L}$ of $2.5 \mathrm{mM}$ dNTPs mix, $0.5 \mu \mathrm{L}$ of each primer $(10 \mathrm{mM}), 0.2 \mu \mathrm{L}$ of Q5 High-Fidelity DNA Polymerase (New England Biolabs, Ipswich, MA, USA), and $2 \mu \mathrm{L}$ of template DNA. The cycling conditions were as follows: $5 \mathrm{~min}$ at $95^{\circ} \mathrm{C}$, followed by 35 cycles at $95^{\circ} \mathrm{C}$ for $30 \mathrm{~s}, 60^{\circ} \mathrm{C}$ for $30 \mathrm{~s}$, and $72{ }^{\circ} \mathrm{C}$ for $30 \mathrm{~s}$, and a final extension at $72{ }^{\circ} \mathrm{C}$ for $10 \mathrm{~min}$. The PCR products were visualized using capillary electrophoresis in QIAxcel Advanced System (Qiagen, Hilden, Germany) with QIAxcel DNA Fast Analysis Cartridge and QX DNA size marker $15 \mathrm{bp}-3 \mathrm{~kb}$ (Figure S3). The PCR product sizes were estimated using the QIAxcel ScreenGel Software (Qiagen, Hilden, Germany). The capillary electrophoresis clearly showed that amplicons are not detected after the third washing (Figure S3).
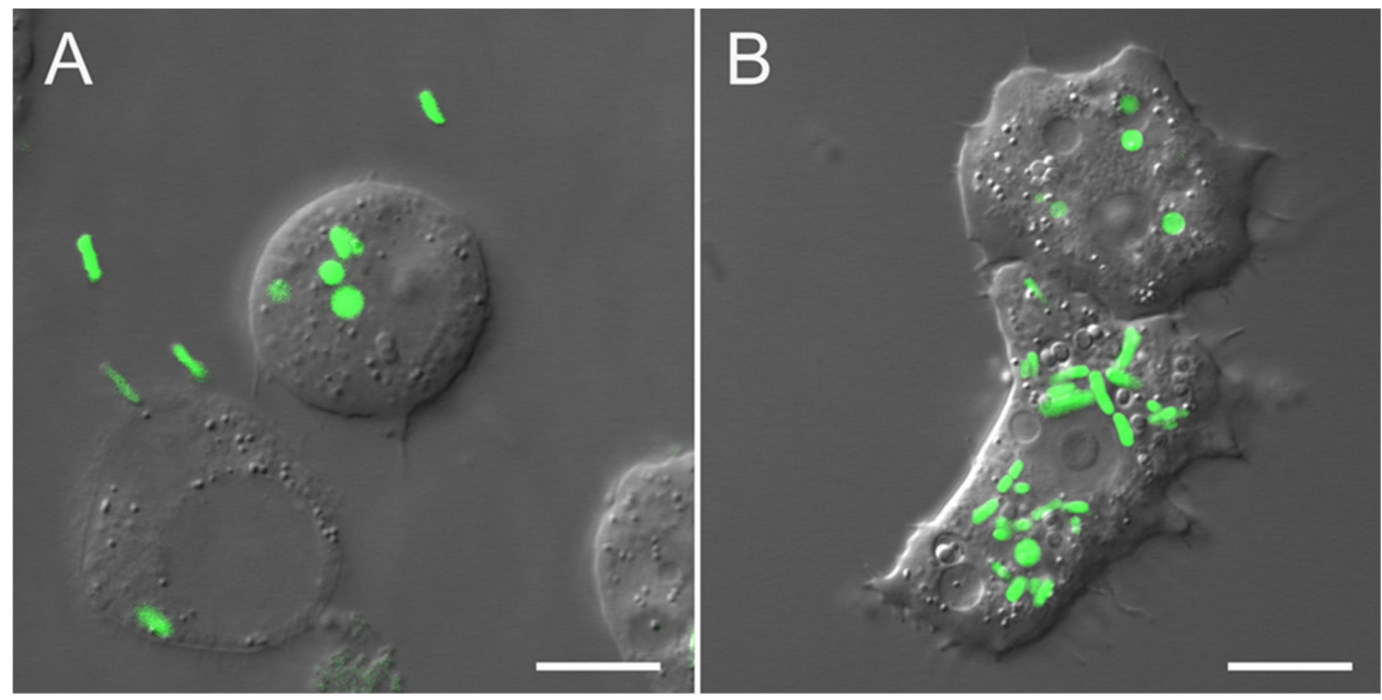

Figure 5. Acanthamoeba castellanii infected with S. Typhimurium (GFP) before (A) and after (B) washing procedures. Confocal laser scanning microscopy: differential interference contrast overlays with single optical GFP fluorescence sections in the green channel. Scale bars: $10 \mu \mathrm{m}$. 
A control Salmonella was cultured under the aforementioned conditions, with certain modifications. The bacteria were grown for $2 \mathrm{~h}$ at $25{ }^{\circ} \mathrm{C}$ in sterile PAS in the absence of Acanthamoeba and washed thrice by centrifugation at $1200 \times g$ for $5 \mathrm{~min}$ at $25^{\circ} \mathrm{C}$.

\subsection{Microscopy}

Salmonella transformed with the eGFP-pBAD plasmid (a gift from Michael Davidson, Addgene plasmid \#54762; http://n2t.net/addgene:54762; RRID:Addgene_54762) was used to confirm intracellular localization. Images of infected cells were acquired every hour using a Zeiss LSM 780 laser scanning confocal microscope equipped with a PlanApochromat $40 \times / 1.3$ Oil DIC or Plan-Apochromat $63 \times / 1.4$ Oil DIC objective (Zeiss, Jena, Germany). Single mages and time-lapse series were acquired using the ZEN 2012 Black software (Zeiss). Differential interference contrast was used for visualization of living cells on a TPMT detector. GFP fluorescence in Salmonella was quantitated by excitation at $488 \mathrm{~nm}$ with the argon laser and an emission at $490-569 \mathrm{~nm}$ in the Channel mode.

\subsection{RNA Extraction and cDNA Library Preparation}

Total RNA was extracted with ExtractRNA reagent (Evrogen, Moscow, Russia). The RNA samples were treated with a TURBO DNA-free ${ }^{\mathrm{TM}}$ kit (Thermo Fisher Scientific, Waltham, MA, USA) following the manufacturer's instructions. The RNA content was determined in a Qubit fluorometer (Thermo Fisher Scientific, Waltham, MA, USA). RNA integrity, purity, and concentration were assessed with a Bioanalyzer 2100 (Agilent Technologies, Santa Clara, CA, USA).

The Cappable-Seq procedure was performed as previously described [24].

Briefly, total RNA from Salmonella $(5 \mu \mathrm{g})$ or Salmonella plus Acanthamoeba $(10 \mu \mathrm{g})$ was capped with $3^{\prime}$-desthiobiotin-GTP using a Vaccinia capping system (New England Biolabs, Ipswich, MA, USA). The RNA was then purified $4 \times$ with RNA wash buffer on the RNA Clean and Concentrator- 5 column (Zymo Research, Irvine, CA, USA) and eluted in $30 \mu \mathrm{L}$ nuclease-free water.

Desthiobiotin-GTP-capped RNA was fragmented by polynucleotide kinase buffer and incubated for $5 \mathrm{~min}$ at $94^{\circ} \mathrm{C}$. The $3^{\prime}$-phosphates were removed from the fragmented RNA with polynucleotide kinase buffer and T4 polynucleotide kinase at $37^{\circ} \mathrm{C}$ for $15 \mathrm{~min}$.

Thereafter $40 \mu \mathrm{L}$ of eluted RNA was added to $40 \mu \mathrm{L}$ hydrophilic streptavidin magnetic beads (New England Biolabs, Ipswich, MA, USA). The RNA-bead mixture was incubated at $25^{\circ} \mathrm{C}$ for $20 \mathrm{~min}$. The RNA-bead mixture was washed twice on a magnetic rack in Buffer A followed by two washes in Buffer B. The biotin-eluted RNA was collected by placing the tube on the magnetic rack. Eluted RNA was cleaned with AMPure XP beads (Beckman Coulter, Brea, CA, USA). Here, we used a single enrichment round to reduce the proportion of rRNA to $<50 \%$. The second enrichment round dramatically decreased RNA yield and left insufficient material for library preparation.

In this study, $8 \%$ to $15 \%$ of all reads in the SA libraries were mapped to the Salmonella genome (Table S1), and the mRNA enrichment level was comparable to that reported in a previous study on the Wolbachia endosymbiont of Brugia malayi [67]. In our study, $30-50 \%$ of total reads were mapped to coding regions. In the control libraries, $38-49 \%$ of total reads were mapped primarily to the $16 \mathrm{~S}$ and $23 \mathrm{~S}$ rRNA genes (Table S3). In the intracellular Salmonella libraries, the proportion of ribosomal transcripts was $\leq 50 \%$ of all reads (Figure S1), and most of them comprised 5.8S eukaryotic rRNA.

The desthiobiotin caps were removed with Thermopol Buffer (New England Biolabs, Ipswich, MA, USA) and RppH (New England Biolabs, Ipswich, MA, USA) at $37^{\circ} \mathrm{C}$ for $60 \mathrm{~min}$. The reaction was terminated by adding $0.5 \mu \mathrm{L}$ of $0.5 \mathrm{M}$ EDTA and heating at $94{ }^{\circ} \mathrm{C}$ for 2 min. The RNA was collected on AMPure beads (Beckman Coulter, Brea, CA, USA) as previously described and washed and eluted in $6 \mu \mathrm{L}$ low TE buffer. A NEBNext small RNA library prep kit (New England Biolabs, Ipswich, MA, USA) was used to generate Illumina sequencing libraries that were then amplified through 15 PCR cycles. All libraries 
were sequenced on an Illumina HiSeq 2000 (50-bp single-end reads; Illumina, San Diego, CA, USA) at the Joint KFU-Riken Laboratory of Kazan Federal University, Kazan, Russia.

All RNA-seq data discussed in this publication have been deposited in NCBI's Gene Expression Omnibus and are available through GEO Series accession number GSE173638.

\section{5. qRT-PCR Analysis}

Biological validation of the transcriptomic analysis was provided by qRT-PCR using

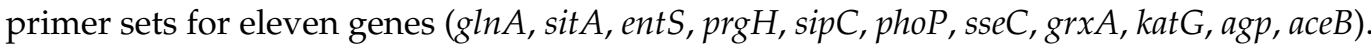
The primers were designed using Vector NTI 9.1.0 (Thermo Fisher Scientific, Waltham, MA, USA) (Table S4). cDNA was synthesized from $1 \mu \mathrm{g}$ RNA of Salmonella control culture or $3 \mu \mathrm{g}$ RNA of Salmonella-Acanthamoeba co-culture using the M-MuLV Reverse Transcriptase (New England Biolabs, Ipswich, MA, USA). Three biological replicates and three technical replicates were used for each sample of two different conditions (Salmonella and SalmonellaAcanthamoeba). qRT-PCR was performed on CFX connect real-time PCR detection system (Bio-Rad, Hercules, CA) and rpoD was used as a reference gene because it demonstrated most stability in our conditions (determined by geNorm among four potential genes) and had the narrowest range of variability according to the Cappable-Seq analysis. A melting curve analysis $\left(55^{\circ} \mathrm{C}\right.$ to $\left.95^{\circ} \mathrm{C}\right)$ was performed after the thermal profile to ensure specificity. PCR efficiency was calculated from the log-linear portion of the standard curves. Differential gene expression and fold changes were determined using REST 2009 software (https: / / www.gene-quantification.de/ rest-2009.html (accessed on 6 July 2021)).

\subsection{Bioinformatic Analysis}

Demultiplexed reads were trimmed against adapters with bbduk (https: / / sourceforge. net/projects/bbmap / (accessed on 16 February 2021)). SortMeRNA v.2.1 [68] was used to remove reads belonging to prokaryote and eukaryote rRNA sequences. Clean reads were initially mapped against the full $A$. castellanii genome (GCF_000313135.1) with Bowtie2 [69] in local mode (L-16) and then mapped against the $S$. Typhimurium 14028s genome (GCA_000022165.1) [70] using similar parameters. The mapped files were converted to bam format using SAMtools [71]. We found that $8 \%$ to $15 \%$ of all reads in SA libraries were mapped to the Salmonella genome (Table S1), and the mRNA enrichment level was comparable to that reported in a previous study on the Wolbachia endosymbiont of Brugia malayi [68]. Proportion of total reads primarily mapped to coding regions accounted $51-62 \%$ for the control Salmonella libraries and $\geq 50 \%$ for the intracellular Salmonella libraries (Table S3, Figure S1).

TSS were identified as previously described [24], with certain modifications. A 0.5-30.5 cutoff range was used in the bam2firstbasegtf.pl script (https:/ / github.com/Ettwiller/TSS (accessed on 16 February 2021)). The number of revealed TSS was used to plot graphs and identify the optimal cutoff parameter. The TSS were clustered with the cluster_tss.pl script and cutoff of 5 .

The genes in the RefSeq annotation divided the TSS into the categories InterS (intergenic TSS with downstream gene in same orientation), InterA (intergenic TSS with downstream gene in opposite orientation), IntraS (intragenic TSS in gene with same orientation), or IntraA (intragenic TSS in gene with opposite orientation) according to Boutard et al. [72]. The Bedtools toolset was used to search for the closest gene and determine its distance from the TSS [73]. Gene activity was determined as the total number of reads belonging to the TSS in the 300-bp gene (operon) region in the direct orientation of the corresponding open reading frame (ORF).

The reads per operon were evaluated with featureCounts in the Rsubread package of $\mathrm{R}$ [74]. Door2 database was used to identify genes in operons [75]. An operons and genes with the original read coverage scores were used for differential gene expression analysis in the DESeq2 package [76]. Genes with FDR $<0.05$, read count $>10$ and fold change $>2$ were determined as significantly differentially expressed. A principal component analysis (PCA) plot was constructed and transformed by the regularized log approach in R. A 
metabolic pathway enrichment analysis was conducted in the fgsea package [77] against the KEGG database (https: / /www.kegg.jp / (accessed on 18 February 2021)). The genes were assigned to COG functional category in eggNOG database v. 4.5 [78].

Supplementary Materials: The following are available online at https:/ /www.mdpi.com/article/10 $.3390 /$ ijms22169077/s1.

Author Contributions: Conceptualization, Y.V.G., S.V.C. and A.O.P.; methodology, Y.V.G., N.E.G. and K.N.D.; software, A.S.B.; investigation, A.S.B., N.E.G. and K.N.D.; resources, N.E.G. and A.O.P.; data curation, A.S.B. and N.E.G.; writing-original draft preparation, A.S.B., S.V.C. and A.O.P.; writing-review and editing, A.O.P., Y.V.G., S.V.C. and K.N.D.; visualization, A.S.B. and K.N.D. All authors have read and agreed to the published version of the manuscript.

Funding: This research received no external funding.

Institutional Review Board Statement: Not applicable.

Informed Consent Statement: Not applicable.

Data Availability Statement: All RNA-seq data discussed in this publication have been deposited in NCBI's Gene Expression Omnibus and are available through GEO Series accession number GSE173638 (available online: https:/ / www.ncbi.nlm.nih.gov / geo/query/acc.cgi?acc=GSE173638) (accessed on 22 August 2021).

Acknowledgments: The experiments on co-cultivation were conducted in the "Persistence of microorganisms" Science Resource Center of the Institute for Cellular and Intracellular Symbiosis, Ural Branch of Russian Academy of Sciences (Orenburg, Russia). Confocal laser scanning microscopy was done using equipment at The Core Facilities Center "Cell and Molecular Technologies in Plant Science" at the Komarov Botanical Institute of Russian Academy of Sciences (St.-Petersburg, Russia). Y.V.G. is grateful to the Ministry of Science and Higher Education of the Russian Federation for their administrative support within the framework of the government assignment for the FRC Kazan Scientific Center of the RAS. The constructive comments and advice of two unknown reviewers were greatly appreciated.

Conflicts of Interest: The authors declare no conflict of interest.

\section{References}

1. European Food Safety Authority (EFSA); European Centre for Disease Prevention and Control (ECDC). The European Union summary report on trends and sources of zoonoses, zoonotic agents and food-borne outbreaks in 2017. EFSA J. 2018, 16, e05500. [CrossRef]

2. Vaerewijck, M.J.M.; Baré, J.; Lambrecht, E.; Sabbe, K.; Houf, K. Interactions of Foodborne Pathogens with Free-living Protozoa: Potential Consequences for Food Safety. Compr. Rev. Food Sci. Food Saf. 2014, 13, 924-944. [CrossRef]

3. Balczun, C.; Scheid, P.L. Free-living amoebae as hosts for and vectors of intracellular microorganisms with public health significance. Viruses 2017, 9, 65. [CrossRef] [PubMed]

4. Pace, M.L. Bacterial mortality and the fate of bacterial production. Hydrobiologia 1988, 159, 41-49. [CrossRef]

5. Hahn, M.W.; Höfle, M.G. Grazing of protozoa and its effect on populations of aquatic bacteria. FEMS Microbiol. Ecol. 2001, 35, 113-121. [CrossRef]

6. Denoncourt, A.M.; Paquet, V.E.; Charette, S.J. Potential role of bacteria packaging by protozoa in the persistence and transmission of pathogenic bacteria. Front. Microbiol. 2014, 5, 240. [CrossRef] [PubMed]

7. Hoffmann, C.; Harrison, C.F.; Hilbi, H. The natural alternative: Protozoa as cellular models for Legionella infection. Cell. Microbiol. 2014, 16, 15-26. [CrossRef]

8. Gaze, W.H.; Burroughs, N.; Gallagher, M.P.; Wellington, E.M.H. Interactions between Salmonella typhimurium and Acanthamoeba polyphaga, and Observation of a New Mode of Intracellular Growth within Contractile Vacuoles. Microb. Ecol. 2003, 46, 358-369. [CrossRef] [PubMed]

9. Douesnard-Malo, F.; Daigle, F. Increased persistence of Salmonella enterica Serovar typhi in the presence of Acanthamoeba castellanii. Appl. Environ. Microbiol. 2011, 77, 7640-7646. [CrossRef] [PubMed]

10. Moreno-Mesonero, L.; Ferrús, M.A.; Moreno, Y. Determination of the bacterial microbiome of free-living amoebae isolated from wastewater by $16 \mathrm{~S}$ rRNA amplicon-based sequencing. Environ. Res. 2020, 190, e109987. [CrossRef]

11. Tezcan-Merdol, D.; Ljungström, M.; Winiecka-Krusnell, J.; Linder, E.; Engstrand, L.; Rhen, M. Uptake and replication of Salmonella enterica in Acanthamoeba rhysodes. Appl. Environ. Microbiol. 2004, 70, 3706-3714. [CrossRef] [PubMed] 
12. Riquelme, S.; Varas, M.; Valenzuela, C.; Velozo, P.; Chahin, N.; Aguilera, P.; Sabag, A.; Labra, B.; Álvarez, S.A.; Chávez, F.P.; et al. Relevant genes linked to virulence are required for Salmonella typhimurium to survive intracellularly in the social amoeba Dictyostelium discoideum. Front. Microbiol. 2016, 7, 1305. [CrossRef] [PubMed]

13. Gourabathini, P.; Brandi, M.T.; Redding, K.S.; Gunderson, J.H.; Berk, S.G. Interactions between food-borne pathogens and protozoa isolated from lettuce and spinach. Appl. Environ. Microbiol. 2008, 74, 2518-2525. [CrossRef] [PubMed]

14. Rehfuss, M.Y.M.; Parker, C.T.; Brandl, M.T. Salmonella transcriptional signature in Tetrahymena phagosomes and role of acid tolerance in passage through the protist. ISME J. 2011, 5, 262-273. [CrossRef] [PubMed]

15. Hautefort, I.; Thompson, A.; Eriksson-Ygberg, S.; Parker, M.L.; Lucchini, S.; Danino, V.; Bongaerts, R.J.M.; Ahmad, N.; Rhen, M.; Hinton, J.C.D. During infection of epithelial cells Salmonella enterica serovar Typhimurium undergoes a time-dependent transcriptional adaptation that results in simultaneous expression of three type 3 secretion systems. Cell. Microbiol. 2008, 10, 958-984. [CrossRef] [PubMed]

16. Westermann, A.J.; Förstner, K.U.; Amman, F.; Barquist, L.; Chao, Y.; Schulte, L.N.; Müller, L.; Reinhardt, R.; Stadler, P.F.; Vogel, J. Dual RNA-seq unveils noncoding RNA functions in host-pathogen interactions. Nature 2016, 529, 496-501. [CrossRef]

17. Srikumar, S.; Kröger, C.; Hébrard, M.; Colgan, A.; Owen, S.V.; Sivasankaran, S.K.; Cameron, A.D.S.; Hokamp, K.; Hinton, J.C.D. RNA-seq Brings New Insights to the Intra-Macrophage Transcriptome of Salmonella Typhimurium. PLoS Pathog. 2015, 11, e1005262. [CrossRef]

18. Noster, J.; Chao, T.C.; Sander, N.; Schulte, M.; Reuter, T.; Hansmeier, N.; Hensel, M. Proteomics of intracellular Salmonella enterica reveals roles of Salmonella pathogenicity island 2 in metabolism and antioxidant defense. PLoS Pathog. 2019, 15, e1007741. [CrossRef]

19. Li, Z.; Liu, Y.; Fu, J.; Zhang, B.; Cheng, S.; Wu, M.; Wang, Z.; Jiang, J.; Chang, C.; Liu, X. Salmonella Proteomic Profiling during Infection Distinguishes the Intracellular Environment of Host Cells. mSystems 2019, 4, e00314-18. [CrossRef] [PubMed]

20. Núñez-Hernández, C.; Tierrez, A.; Ortega, A.D.; Pucciarelli, M.G.; Godoy, M.; Eisman, B.; Casadesús, J.; García-del Portillo, F. Genome expression analysis of nonproliferating intracellular Salmonella enterica serovar Typhimurium unravels an acid pH-dependent PhoP-PhoQ response essential for dormancy. Infect. Immun. 2013, 81, 154-165. [CrossRef]

21. Bleasdale, B.; Lott, P.J.; Jagannathan, A.; Stevens, M.P.; Birtles, R.J.; Wigley, P. The Salmonella pathogenicity island 2-encoded type III secretion system is essential for the survival of Salmonella enterica serovar typhimurium in free-living amoebae. Appl. Environ. Microbiol. 2009, 75, 1793-1795. [CrossRef]

22. Feng, Y.; Hsiao, Y.H.; Chen, H.L.; Chu, C.; Tang, P.; Chiu, C.H. Apoptosis-like cell death induced by Salmonella in Acanthamoeba rhysodes. Genomics 2009, 94, 132-137. [CrossRef]

23. Sharma, C.M.; Hoffmann, S.; Darfeuille, F.; Reignier, J.; Findeiß, S.; Sittka, A.; Chabas, S.; Reiche, K.; Hackermüller, J.; Reinhardt, R.; et al. The primary transcriptome of the major human pathogen Helicobacter pylori. Nature 2010, 464, 250-255. [CrossRef] [PubMed]

24. Ettwiller, L.; Buswell, J.; Yigit, E.; Schildkraut, I. A novel enrichment strategy reveals unprecedented number of novel transcription start sites at single base resolution in a model prokaryote and the gut microbiome. BMC Genom. 2016, 17, 199. [CrossRef] [PubMed]

25. Bjarnason, J.; Southward, C.M.; Surette, M.G. Genomic profiling of iron-responsive genes in Salmonella enterica serovar Typhimurium by high-throughput screening of a random promoter library. J. Bacteriol. 2003, 185, 4973-4982. [CrossRef]

26. Johnson, R.; Byrne, A.; Berger, C.N.; Klemm, E.; Crepin, V.F.; Dougan, G.; Frankel, G. The type III secretion system effector SptP of Salmonella enterica serovar Typhi. J. Bacteriol. 2017, 199, e00647-16. [CrossRef] [PubMed]

27. Mirold, S.; Ehrbar, K.; Weissmüller, A.; Prager, R.; Tschäpe, H.; Rüssmann, H.; Hardt, W.D. Salmonella host cell invasion emerged by acquisition of a mosaic of separate genetic elements, including Salmonella pathogenicity island 1 (SPI1), SPI5, and sopE2. J. Bacteriol. 2001, 183, 2348-2358. [CrossRef]

28. Eriksson, S.; Lucchini, S.; Thompson, A.; Rhen, M.; Hinton, J.C.D. Unravelling the biology of macrophage infection by gene expression profiling of intracellular Salmonella enterica. Mol. Microbiol. 2003, 47, 103-118. [CrossRef] [PubMed]

29. Steeb, B.; Claudi, B.; Burton, N.A.; Tienz, P.; Schmidt, A.; Farhan, H.; Mazé, A.; Bumann, D. Parallel Exploitation of Diverse Host Nutrients Enhances Salmonella Virulence. PLoS Pathog. 2013, 9, e1003301. [CrossRef] [PubMed]

30. Diacovich, L.; Lorenzi, L.; Tomassetti, M.; Méresse, S.; Gramajo, H. The infectious intracellular lifestyle of salmonella enterica relies on the adaptation to nutritional conditions within the salmonella-containing vacuole. Virulence 2017, 8, 975-992. [CrossRef] [PubMed]

31. Fang, F.C.; Libby, S.J.; Castor, M.E.; Fung, A.M. Isocitrate lyase (AceA) is required for Salmonella persistence but not for acute lethal infection in mice. Infect. Immun. 2005, 73, 2547-2549. [CrossRef]

32. Ahn, S.; Jung, J.; Jang, I.A.; Madsen, E.L.; Park, W. Role of glyoxylate shunt in oxidative stress response. J. Biol. Chem. 2016, 291, 11928-11938. [CrossRef]

33. Fitzsimmons, L.; Liu, L.; Porwollik, S.; Chakraborty, S.; Desai, P.; Tapscott, T.; Henard, C.; McClelland, M.; Vazquez-Torres, A. Zinc-dependent substrate-level phosphorylation powers Salmonella growth under nitrosative stress of the innate host response. PLoS Pathog. 2018, 14, e1007388. [CrossRef]

34. Frawley, E.R.; Crouch, M.L.V.; Bingham-Ramos, L.K.; Robbins, H.F.; Wang, W.; Wright, G.D.; Fang, F.C. Iron and citrate export by a major facilitator superfamily pump regulates metabolism and stress resistance in Salmonella Typhimurium. Proc. Natl. Acad. Sci. USA 2013, 110, 12054-12059. [CrossRef] [PubMed] 
35. Dandekar, T.; Fieselmann, A.; Fischer, E.; Popp, J.; Hensel, M.; Noster, J. Salmonella-how a metabolic generalist adopts an intracellular lifestyle during infection. Front. Cell. Infect. Microbiol. 2014, 4. [CrossRef]

36. Turnbull, A.L.; Surette, M.G. Cysteine biosynthesis, oxidative stress and antibiotic resistance in Salmonella typhimurium. Res. Microbiol. 2010, 161, 643-650. [CrossRef]

37. Slonczewski, J. Stress Responses: pH. In Encyclopedia of Microbiology, 3rd ed.; Konopka, A., Ed.; Academic Press: Cambridge, MA, USA, 2009; Volume 3, pp. 477-484.

38. Dalebroux, Z.D.; Matamouros, S.; Whittington, D.; Bishop, R.E.; Miller, S.I. PhoPQ regulates acidic glycerophospholipid content of the Salmonella Typhimurium outer membrane. Proc. Natl. Acad. Sci. USA 2014, 111, 1963-1968. [CrossRef] [PubMed]

39. Karlinsey, J.E.; Stepien, T.A.; Mayho, M.; Singletary, L.A.; Bingham-Ramos, L.K.; Brehm, M.A.; Greiner, D.L.; Shultz, L.D.; Gallagher, L.A.; Bawn, M.; et al. Genome-wide Analysis of Salmonella enterica serovar Typhi in Humanized Mice Reveals Key Virulence Features. Cell Host Microbe 2019, 26, 426-434.e6. [CrossRef]

40. Schaible, U.E.; Kaufmann, S.H.E. Iron and microbial infection. Nat. Rev. Microbiol. 2004, 2, 946-953. [CrossRef] [PubMed]

41. Litwin, C.M.; Calderwood, S.B. Role of iron in regulation of virulence genes. Clin. Microbiol. Rev. 1993, 6, 137-149. [CrossRef] [PubMed]

42. Khajanchi, B.K.; Xu, J.; Grim, C.J.; Ottesen, A.R.; Ramachandran, P.; Foley, S.L. Global transcriptomic analyses of Salmonella enterica in Iron-depleted and iron-rich growth conditions. BMC Genom. 2019, 20, 490. [CrossRef]

43. Crouch, M.L.V.; Castor, M.; Karlinsey, J.E.; Kalhorn, T.; Fang, F.C. Biosynthesis and IroC-dependent export of the siderophore salmochelin are essential for virulence of Salmonella enterica serovar Typhimurium. Mol. Microbiol. 2008, 67, 971-983. [CrossRef] [PubMed]

44. Nairz, M.; Ferring-Appel, D.; Casarrubea, D.; Sonnweber, T.; Viatte, L.; Schroll, A.; Haschka, D.; Fang, F.C.; Hentze, M.W.; Weiss, G.; et al. Iron regulatory proteins mediate host resistance to Salmonella infection. Cell Host Microbe 2015, 18, 254-261. [CrossRef] [PubMed]

45. Ray, P.D.; Huang, B.W.; Tsuji, Y. Reactive oxygen species (ROS) homeostasis and redox regulation in cellular signaling. Cell. Signal. 2012, 24, 981-990. [CrossRef] [PubMed]

46. Dunn, J.D.; Bosmani, C.; Barisch, C.; Raykov, L.; Lefrançois, L.H.; Cardenal-Muñoz, E.; López-Jiménez, A.T.; Soldati, T. Eat prey, live: Dictyostelium discoideum as a model for cell-autonomous defenses. Front. Immunol. 2018, 8, 1906. [CrossRef] [PubMed]

47. Ezraty, B.; Gennaris, A.; Barras, F.; Collet, J.F. Oxidative stress, protein damage and repair in bacteria. Nat. Rev. Microbiol. 2017, 15, 385-396. [CrossRef]

48. Zheng, J.; Cui, S.; Meng, J. Effect of transcriptional activators RamA and SoxS on expression of multidrug efflux pumps AcrAB and AcrEF in fluoroquinolone-resistant Salmonella Typhimurium. J. Antimicrob. Chemother. 2009, 63, 95-102. [CrossRef]

49. McLean, S.; Bowman, L.A.H.; Poole, R.K. KatG from Salmonella Typhimurium is a peroxynitritase. FEBS Lett. 2010, 584, 1628-1632. [CrossRef] [PubMed]

50. Festa, R.A.; Thiele, D.J. Copper at the Front Line of the Host-Pathogen Battle. PLoS Pathog. 2012, 8, e1002887. [CrossRef]

51. Kapetanovic, R.; Bokil, N.J.; Achard, M.E.S.; Ong, C.L.Y.; Peters, K.M.; Stocks, C.J.; Phan, M.D.; Monteleone, M.; Schroder, K.; Irvine, K.M.; et al. Salmonella employs multiple mechanisms to subvert the TLR-inducible zinc-mediated antimicrobial response of human macrophages. FASEB J. 2016, 30, 1901-1912. [CrossRef]

52. Hao, X.; Lüthje, F.L.; Qin, Y.; McDevitt, S.F.; Lutay, N.; Hobman, J.L.; Asiani, K.; Soncini, F.C.; German, N.; Zhang, S.; et al. Survival in amoeba-A major selection pressure on the presence of bacterial copper and zinc resistance determinants? Identification of a "copper pathogenicity island". Appl. Microbiol. Biotechnol. 2015, 99, 5817-5824. [CrossRef] [PubMed]

53. Rome, K.; Borde, C.; Taher, R.; Cayron, J.; Lesterlin, C.; Gueguen, E.; De Rosny, E.; Rodrigue, A. The Two-Component System ZraPSR Is a Novel ESR that Contributes to Intrinsic Antibiotic Tolerance in Escherichia coli. J. Mol. Biol. 2018, 430, 4971-4985. [CrossRef] [PubMed]

54. Velayudhan, J.; Karlinsey, J.E.; Frawley, E.R.; Becker, L.A.; Nartea, M.; Fang, F.C. Distinct roles of the Salmonella enterica serovar typhimurium CyaY and YggX proteins in the biosynthesis and repair of iron-sulfur clusters. Infect. Immun. 2014, 82, 1390-1401. [CrossRef]

55. Outten, F.W.; Djaman, O.; Storz, G. A suf operon requirement for Fe-S cluster assembly during iron starvation in Escherichia coli. Mol. Microbiol. 2004, 52, 861-872. [CrossRef] [PubMed]

56. De la Cruz, M.A.; Pérez-Morales, D.; Palacios, I.J.; Fernández-Mora, M.; Calva, E.; Bustamante, V.H. The two-component system CpxR/A represses the expression of Salmonella virulence genes by affecting the stability of the transcriptional regulator HilD. Front. Microbiol. 2015, 6, 807. [CrossRef]

57. Ong, S.Y.; Ng, F.L.; Badai, S.S.; Yuryev, A.; Alam, M. Analysis and construction of pathogenicity island regulatory pathways in Salmonella enterica serovar Typhi. J. Integr. Bioinform. 2010, 7, 145. [CrossRef]

58. Lou, L.; Zhang, P.; Piao, R.; Wang, Y. Salmonella Pathogenicity Island 1 (SPI-1) and Its Complex Regulatory Network. Front. Cell. Infect. Microbiol. 2019, 9, 270. [CrossRef]

59. Mangan, M.W.; Lucchini, S.; Cróinín, T.Ó.; Fitzgerald, S.; Hinton, J.C.D.; Dorman, C.J. Nucleoid-associated protein HU controls three regulons that coordinate virulence, response to stress and general physiology in Salmonella enterica serovar Typhimurium. Microbiology 2011, 157, 1075-1087. [CrossRef]

60. Wang, Y.; Yi, L.; Zhang, J.; Sun, L.; Wen, W.; Zhang, C.; Wang, S. Functional analysis of superoxide dismutase of Salmonella typhimurium in serum resistance and biofilm formation. J. Appl. Microbiol. 2018, 125, 1526-1533. [CrossRef] 
61. Lee, Y.H.; Kim, S.; Helmann, J.D.; Kim, B.H.; Park, Y.K. RaoN, a small RNA encoded within Salmonella pathogenicity island-11, confers resistance to macrophage-induced stress. Microbiology 2013, 159, 1366-1378. [CrossRef]

62. Löber, S.; Jäckel, D.; Kaiser, N.; Hensel, M. Regulation of Salmonella pathogenicity island 2 genes by independent environmental signals. Int. J. Med Microbiol. 2006, 296, 435-447. [CrossRef]

63. Lim, S.; Kim, M.; Choi, J.; Ryu, S. A mutation in tdcA attenuates the virulence of Salmonella enterica serovar Typhimurium. Mol. Cells 2010, 29, 509-517. [CrossRef] [PubMed]

64. Kim, M.; Lim, S.; Kim, D.; Choy, H.E.; Ryu, S. A tdcA mutation reduces the invasive ability of Salmonella enterica serovar typhimurium. Mol. Cells 2009, 28, 389-395. [CrossRef] [PubMed]

65. Ibarra, J.A.; Knodler, L.A.; Sturdevant, D.E.; Virtaneva, K.; Carmody, A.B.; Fischer, E.R.; Porcella, S.F.; Steele-Mortimer, O. Induction of Salmonella pathogenicity island 1 under different growth conditions can affect Salmonella-host cell interactions in vitro. Microbiology 2010, 156, 1120-1133. [CrossRef] [PubMed]

66. Maloy, S.R.; Nunn, W.D. Genetic regulation of the glyoxylate shunt in Escherichia coli K-12. J. Bacteriol. 1982, 149, 173-180. [CrossRef]

67. Luck, A.N.; Slatko, B.E.; Foster, J.M. Removing the needle from the haystack: Enrichment of Wolbachia endosymbiont transcripts from host nematode RNA by Cappable-seq ${ }^{\mathrm{TM}}$. PLoS ONE 2017, 12, e0173186. [CrossRef]

68. Kopylova, E.; Noé, L.; Touzet, H. SortMeRNA: Fast and accurate filtering of ribosomal RNAs in metatranscriptomic data. Bioinformatics 2012, 28, 3211-3217. [CrossRef]

69. Langmead, B.; Salzberg, S.L. Fast gapped-read alignment with Bowtie 2. Nat. Methods 2012, 9, 357-359. [CrossRef]

70. Jarvik, T.; Smillie, C.; Groisman, E.A.; Ochman, H. Short-term signatures of evolutionary change in the Salmonella enterica serovar Typhimurium 14028 genome. J. Bacteriol. 2010, 192, 560-567. [CrossRef]

71. Li, H.; Handsaker, B.; Wysoker, A.; Fennell, T.; Ruan, J.; Homer, N.; Marth, G.; Abecasis, G.; Durbin, R. The Sequence Alignment/Map format and SAMtools. Bioinformatics 2009, 25, 2078-2079. [CrossRef]

72. Boutard, M.; Ettwiller, L.; Cerisy, T.; Alberti, A.; Labadie, K.; Salanoubat, M.; Schildkraut, I.; Tolonen, A.C. Global repositioning of transcription start sites in a plant-fermenting bacterium. Nat. Commun. 2016, 7, 13783. [CrossRef]

73. Quinlan, A.R.; Hall, I.M. BEDTools: A flexible suite of utilities for comparing genomic features. Bioinformatics 2010, 26, 841-842. [CrossRef] [PubMed]

74. Liao, Y.; Smyth, G.K.; Shi, W. FeatureCounts: An efficient general purpose program for assigning sequence reads to genomic features. Bioinformatics 2014, 30, 923-930. [CrossRef]

75. Mao, X.; Ma, Q.; Zhou, C.; Chen, X.; Zhang, H.; Yang, J.; Mao, F.; Lai, W.; Xu, Y. DOOR 2.0: Presenting operons and their functions through dynamic and integrated views. Nucleic Acids Res. 2014, 42, D654-D659. [CrossRef]

76. Love, M.I.; Huber, W.; Anders, S. Moderated estimation of fold change and dispersion for RNA-seq data with DESeq2. Genome Biol. 2014, 15, 550. [CrossRef] [PubMed]

77. Korotkevich, G.; Sukhov, V.; Budin, N.; Shpak, B.; Artyomov, M.; Sergushichev, A. Fast gene set enrichment analysis. bioRxiv 2016. [CrossRef]

78. Huerta-Cepas, J.; Szklarczyk, D.; Forslund, K.; Cook, H.; Heller, D.; Walter, M.C.; Rattei, T.; Mende, D.R.; Sunagawa, S.; Kuhn, M.; et al. EGGNOG 4.5: A hierarchical orthology framework with improved functional annotations for eukaryotic, prokaryotic and viral sequences. Nucleic Acids Res. 2016, 44, D286-D293. [CrossRef] [PubMed] 